\title{
Gas separation properties of new polyoxadiazole and polytriazole membranes
}

\author{
E. R. Hensema*, M. E. R. Sena**, M. H. V. Muldert and \\ C. A. Smolders
}

\author{
University of Twente, Department of Chemical Technology, Janeiro/UFRJ, PO Box 217, \\ 7500 AE Enschede, The Netherlands \\ * Instituto de Macromolécules, Universidade do Rio de llha do Funao, Centro de \\ Tecnologia, CEP 21945, Rio de Janeiro, Brasil
}

The gas separation properties of new aromatic poly-1,2,4-triazole and poly-1,3,4-oxadiazole membranes have been systematically investigated. Various functional groups were incorporated as pendent groups onto the polymer backbone of poly-1,2,4-triazoles. A wide permeability/selectivity spectrum was covered with the choice of functional groups incorporated into the polymer backbone of poly-1,3,4-oxadiazoles. High permeabilities were found for poly-1,3,4-oxadiazoles with a 1,1,3-trimethyl-3-phenylindane (PIDA-POD) and a $4,4^{\prime}\left(2,2^{\prime}\right.$-diphenyl) hexafluor propane (HF-POD) unit in the polymer backbone, while incorporation of a 4,4'-diphenyl ether unit (DPE-POD) results in a polymer with a low permeability but an extremely high selectivity. While the permeabilities vary over four orders of magnitude, the solubility remains almost constant and, therefore, the increase in permeability is mainly due to an increase in diffusivity. The permeability is discussed in terms of the polymer free volume.

Keywords: poly-1,3,4-oxadiazoles; poly-1,2,4-triazoles; membranes; permeation; free volume

\begin{tabular}{|c|c|c|c|}
\hline \multicolumn{2}{|c|}{ Nomenclature } & $\alpha$ & Selectivity \\
\hline$P$ & Permeability (Barrer) $\left(1\right.$ Barrer $=10^{-10}$ & $\Delta w$ & Relative weight loss (wt \%) \\
\hline & $\left.\mathrm{cm}^{3}(\mathrm{STP}) \mathrm{cm} \mathrm{cm}^{-2} \mathrm{~s}^{-1} \mathrm{cmHg}^{-1}\right)$ & $T_{\mathrm{g}}$ & Glass transition temperature $\left({ }^{\circ} \mathrm{C}\right)$ \\
\hline$D$ & Diffusion coefficient $\left(\mathrm{cm}^{2} \mathrm{~s}^{-1}\right)$ & & Specific volume $\left(\mathrm{cm}^{3} \mathrm{~g}^{-1}\right)$ \\
\hline$D_{0}$ & Pre-exponential value of diffusivity & $V_{\mathrm{f}}$ & Free volume $\left(\mathrm{cm}^{3} \mathrm{~g}^{-1}\right)$ \\
\hline$A, B$ & Parameters depending on the type of gas & $V_{\mathrm{w}}$ & Van der Waals volume $\left(\mathrm{cm}^{3} \mathrm{~g}^{-1}\right)$ \\
\hline$S$ & Solubility $\left(\mathrm{cm}^{3}\right.$ (STP) $\left.\mathrm{cm}^{-3} \mathrm{~cm} \mathrm{Hg}^{-1}\right)$ & $V_{0}$ & Volume occupied by polymer chains \\
\hline$\Theta$ & Time lag (s) & & $\left(\mathrm{cm}^{3} \mathrm{~g}^{-1}\right)$ \\
\hline$l$ & Membrane thickness $(\mathrm{cm})$ & $E_{\mathrm{r}}$ & Thermal expansivity of a polymer in the \\
\hline$V$ & Calibrated volume $\left(\mathrm{cm}^{3}\right)$ & & rubbery state $\left(\mathrm{cm}^{3} \mathrm{~mol}^{-1} \mathrm{~K}^{-1}\right)$ \\
\hline$X$ & Gas concentration in the feed (vol\%) & $E_{\mathrm{c}}$ & Thermal expansivity of a polymer in the \\
\hline$Y$ & Gas concentration in the permeate (vol\%) & & crystalline state $\left(\mathrm{cm}^{3} \mathrm{~mol}^{-1} \mathrm{~K}^{-}\right)$ \\
\hline$\Lambda p$ & $\begin{array}{l}\text { Pressure increase in the calibrated volume } \\
(\mathrm{mmHg})\end{array}$ & $E_{\mathrm{g}}$ & $\begin{array}{l}\text { Thermal expansivity of a polymer in the } \\
\text { glassy state }\left(\mathrm{cm}^{3} \mathrm{~mol}^{1} \mathrm{~K}^{-1}\right)\end{array}$ \\
\hline$\Delta t$ & Time needed for pressure increase $\Delta p$ (s) & Sul & pts \\
\hline$P_{f}$ & Feed pressure $(\mathrm{mmHg})$ & f & Feed side of the membrane \\
\hline 76 & Pressure correction factor $(\mathrm{cmHg})$ & $\mathrm{p}$ & Permeate side of the membrane \\
\hline
\end{tabular}

\section{Introduction}

Today's gas separation membranes are mostly made of conventional high-performance polymers, like poly-

\footnotetext{
* Present address: Ciba-Geigy AG, Central Research Laboratories $\mathrm{CH}-4002$ Basel, Switzerland

† To whom correspondence should be addressed
}

ethersulfone and polyphenylene oxide. The next generation of commercial membranes is likely to be made from 'tailor-made' polymers allowing high permeabilities and selectivities, since current research is dedicated to the development of these materials. For example, polyimides containing the diphenylhexafluoroisopropylidene unit are known for their good gas separation characteristics $^{1}$. Another interesting material, allowing 
exceptional high fluxes, is poly(1-trimethylsilyl-1propyne), PTMSP. Surface fluorination of this material results in higher selectivities without losing too much of the unusual high permeability ${ }^{2}$.

In our laboratory, related poly-1,2,4-triazoles and poly-1,3,4-oxadiazoles are studied as new 'tailor-made' membrane materials. In particular, poly $[p-, m$-phenylene-(4-phenyl)-1,2,4-triazole] is known for its excellent gas separation properties ${ }^{3}$.

In this research project the gas separation properties of poly-1,2,4-triazoles and poly-1,3,4-oxadiazoles are studied. In direct syntheses various related poly-1,2,4triazoles and poly-1,3,4-oxadiazoles were prepared and their gas separation properties were studied as a function of their macromolecular structure and resulting physical properties. The polymers studied are represented in Figure 1.

\section{Experimental}

\section{Materials}

The syntheses and properties of these related thermally stable and chemically resistant polymers are reported elsewhere ${ }^{4,5}$. All other chemicals were supplied by Merck or Janssen Chimica, and were used as received.

Random polv[p-, m-phenylene-(4-phenyl)-1,2,4-triazoles]

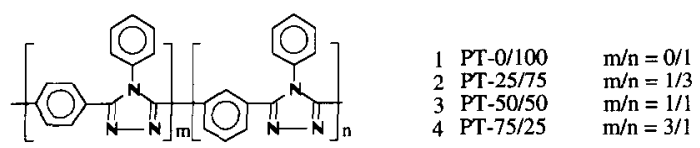

Alternating poly[p-, m-phenylene-(4-phenyl)-1,2,4-triazoles]

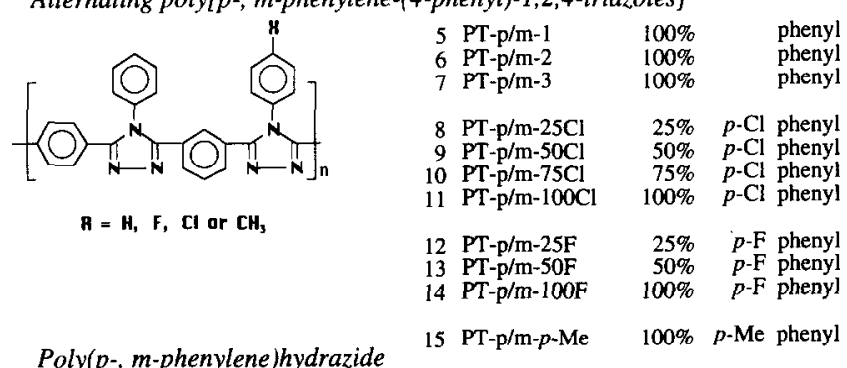

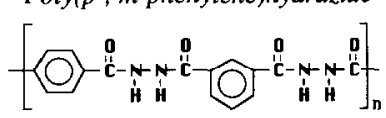

$16 \mathrm{PH}-\mathrm{p} / \mathrm{m}-1$

Poly-1,3,4-oxadiazoles

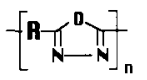

17 TI-POD

18 CH-POD

19 PIDA-POD

20 HF-POD

21 DPE-POD
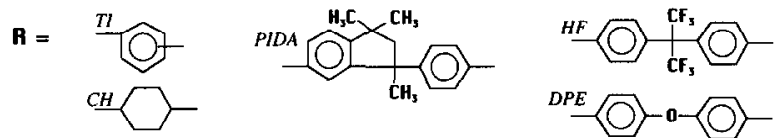

Figure 1 Random and alternating poly-1,2,4-triazoles, polyhydrazide and poly-1,3,4-oxadiazoles studied as new gas separation membrane materials $\mathbf{s}^{3,4}$. TI-POD is a random copolymer using a $50 / 50 \mathrm{~mol} \%$ monomer mixture of terephthalic and isophthalic acids while HF/DPE-POD is a random copolymer using a $40 / 60$ mol\% monomer mixture of HF and DPE dicarboxylic acids

\section{Preparation of homogeneous membranes}

\section{Poly-1,2,4-triazoles}

Homogeneous poly-1,2,4-triazole membranes (polymers 1 to 15 , see Figure I) were prepared from a $10-15 \mathrm{wt} \%$ polymer solution in formic acid. Inhomogeneities were removed from the solution by filtration through a $5 \mu \mathrm{m}$ filter. The solution was cast onto a glass plate using casting knives with slit heights of $0.2,0.3$ and $0.5 \mathrm{~mm}$. Prior to use the glass plate was scrupulously cleaned with chromic acid. After casting, the solvent was evaporated in a nitrogen atmosphere at room temperature. The glass plate was then immersed in a water bath and the poly-1,2,4-triazole membrane was removed easily from the glass plate. Transparent films were obtained with thicknesses between 20 and $60 \mu \mathrm{m}$. The membranes were dried in a vacuum oven for at least $24 \mathrm{~h}$ at $150^{\circ} \mathrm{C}$.

\section{Poly ( $p$-,m-phenylene $)$ hydrazide}

Homogeneous polyhydrazide membranes (polymer 16, see Figure l) were cast from a $10-15 \mathrm{wt} \%$ solution in DMSO (dimethyl sulfoxide) using casting knives with slit heights of 0.3 and $0.5 \mathrm{~mm}$. The solvent was evaporated in a nitrogen atmosphere at $80^{\circ} \mathrm{C}$.

\section{Poly-1,3,4-oxadiazoles}

A $5 \mathrm{wt} \%$ solution of TI-POD (17) in concentrated sulfuric acid was cast onto a glass plate followed by immersion precipitation in $50 \mathrm{wt} \%$ water-diluted sulfuric acid solution. The membranes were then rinsed in demineralized water for at least $24 \mathrm{~h}$ and then dried in a vacuum oven at $150^{\circ} \mathrm{C}$ for at least $24 \mathrm{~h}$. Transparent TI-POD films were obtained.

For CH-POD (18) and DPE-POD (21), the same procedure as for the poly-1,2,4-triazoles was used. PIDA-POD (19) and HF-POD (20) were cast from trifluoroacetic acid solution while HF/DPE-POD membranes were cast from an NMP ( $N$-methyl-2pyrrolidinone) solution followed by evaporation of the solvent at $150^{\circ} \mathrm{C}$ in a nitrogen atmosphere.

\section{Characterization}

\section{Differential scanning calorimetry (d.s.c.)}

D.s.c. measurements were performed on a Perkin-Elmer DSC 4 apparatus in combination with a System 4 microprocessor controller and a thermal analysis data station (TADS), model 3700 . The polymer samples were placed in aluminium sample pans and the temperature was increased with a heating rate of $20^{\circ} \mathrm{C} \mathrm{min}^{-1}$ from 100 to $400^{\circ} \mathrm{C}$ under a nitrogen purge gas stream. The samples were cooled at a rate of $320^{\circ} \mathrm{C} \mathrm{min}^{-1}$ to $100^{\circ} \mathrm{C}$ and a second run was recorded from 100 to $450^{\circ} \mathrm{C}$ again with a heating rate of $20^{\circ} \mathrm{C} \mathrm{min}-1$. At the glass transition temperature $\left(T_{\mathrm{g}}\right)$, the midpoint of the transition was taken, calculated by means of the TADS software.

\section{Thermogravimetric analysis (t.g.a.)}

T.g.a. experiments were carried out on a Perkin-Elmer TGS-2 combination with a System 4 microprocessor controller and a TADS, model 3700 . Experiments were carried out under a nitrogen purge gas stream from 50 to $600^{\circ} \mathrm{C}$. The temperature of the polymer samples was 
increased with a heating rate of $20^{\circ} \mathrm{C} \mathrm{min}^{-1}$. Weight loss between 200 and $400^{\circ} \mathrm{C}$ was attributed to the formation of water due to a ring closure reaction of unclosed 1,2,4-triazole groups. This weight loss was calculated by means of the TADS software.

\section{Density}

The density of the polymers 1 to 17 was determined using a density gradient column of tetrachloromethane and cyclohexanone. For the polymers 18 to 22 an $\mathrm{NaBr}-$ water column was used. The densities were verified by extensiometric methods.

\section{Gas permeation experiments}

Gas transport properties of polyhydrazide, poly-1,2,4triazole and poly-1,3,4-oxadiazole membranes for single gases $\left(\mathrm{O}_{2}, \mathrm{~N}_{2}, \mathrm{CH}_{4}\right.$ and $\left.\mathrm{CO}_{2}\right)$ and gas mixtures of various compositions $\left(\mathrm{CH}_{4}\right.$ and $\left.\mathrm{CO}_{2}\right)$ were determined on two set-ups on which permeability and diffusivity were determined using standard procedures ${ }^{6}$.

On the first set-up ${ }^{7}$, steady-state permeability and selectivity towards carbon dioxide/methane mixtures were determined (see Figure 2 for a schematic representation). Permeability on this set-up was determined by an accurate measurement of the pressure increase with time in a calibrated volume at the vacuated downstream side of the membrane. The carbon dioxide permeability $P_{\mathrm{CO}_{2}}$ is defined as:

$P_{\mathrm{CO}_{2}}=\frac{l \cdot V \cdot Y_{\mathrm{CO}_{2}, \mathrm{p}}}{A \cdot P_{\mathrm{f}} X_{\mathrm{CO}_{2}, \mathrm{f}} 76} \cdot \frac{\Delta p}{\Delta t}$

and the selectivity is determined using gas chromatography and is defined as:

$\alpha_{\mathrm{CO}_{2} / \mathrm{CH}_{4}}=\frac{Y_{\mathrm{CO}_{2}, \mathrm{p}} / Y_{\mathrm{CH}_{4}, \mathrm{p}}}{X_{\mathrm{CO}_{2}, \mathrm{f}} / X_{\mathrm{CH}_{4}, \mathrm{f}}}$

where $P_{\mathrm{CO}_{2}}$ is the permeability for $\mathrm{CO}_{2}\left(\mathrm{~cm}^{3}(\mathrm{STP}) \mathrm{cm}\right.$ $\left.\mathrm{cm}^{-2} \mathrm{~s}^{-1} \mathrm{~cm} \mathrm{Hg}^{-1}\right), l$ is the thickness of the membrane (cm), $V$ is the calibrated volume $\left(\mathrm{cm}^{3}\right), \quad Y_{\mathrm{CO}_{2}, \mathrm{p}}$ and $Y_{\mathrm{CH}_{4}, \mathrm{p}}$ are the $\mathrm{CO}_{2}$ and $\mathrm{CH}_{4}$ contents in the permeate ( $\mathrm{vol} \%$ ) respectively, $\Delta p$ is the pressure increase $(\mathrm{mmHg})$ in the permeate volume during $\Delta t, A$ is the membrane area $\left(\mathrm{cm}^{2}\right), X_{\mathrm{CO}_{2}, \mathrm{f}}$ and $X_{\mathrm{CH}_{4}, \mathrm{f}}$ are the $\mathrm{CO}_{2}$ and $\mathrm{CH}_{4}$ content in the feed (vol\%) respectively, $P_{\mathrm{f}}$ is the feed pressure ( $\mathrm{mmHg}$ ), $\Delta t$ is the time (s) needed for pressure

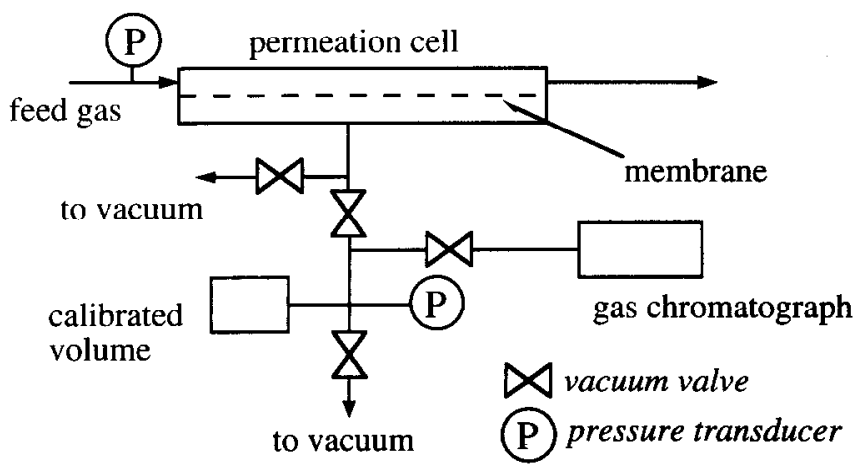

Figure 2 Schematic drawing of the testing apparatus for the gas separation and time-lag measurements of $\mathrm{CO}_{2} / \mathrm{CH}_{4}$ gas mixtures and single gases increase $\Delta p$ and 76 is a pressure correction factor $(\mathrm{cmHg}) . P$ is expressed in Barrer (1 Barrer $=10^{10} \mathrm{~cm}^{3}$ (STP) $\left.\mathrm{cm} \mathrm{cm}^{-2} \mathrm{~s}^{-1} \mathrm{~cm} \mathrm{Hg}^{-1}\right)$. Gas mixtures consisting of $25 \mathrm{vol} \% \mathrm{CO}_{2}$ and 75 vol\% $\mathrm{CH}_{4}$ were applied unless stated differently. The downstream side is vacuum and in all cases a pressure difference of 6 bar over the membrane is applied.

Permeability and selectivity measurements were started immediately after the membranes were put into the cells. Since methane is the slower permeating species, small quantities of methane are present in the permeate immediately after the start of an experiment resulting in initially high selectivity values. Constant and reproducible values are found after approximately $24 \mathrm{~h}$ when a steady state is reached. These steady-state values are reported.

The same set-up was used to determine the permeability of oxygen, nitrogen, carbon dioxide and methane as single gases. In this way the ideal selectivity values of oxygen/nitrogen and of carbon dioxide/ methane were obtained. The ideal selectivity is defined as the ratio of the pure gas permeabilities:

$\alpha_{i j, \text { ideal }}=P_{i} / P_{j}$

A second similar set-up was used to determine permeability and diffusion coefficients by means of 'time-lag' measurements (see Figure 2).

Both set-ups are computer-controlled and were calibrated using a polyester standard film (Standard Reference Material 1470) of the National Bureau of Standards in Washington DC, USA.

In the dead-end cells used in a previous study $^{3}$, soap-film capillary meters were used for the permeability determination. These were not used here since permeability values are relatively small and do not allow an accurate determination by this method.

\section{Results and discussion}

The aim of this paper is to study the influence of the macromolecular structure of the related polyhydrazide, poly-1,2,4-triazoles and poly-1,3,4-oxadiazoles on the gas separation properties. The reproducibility of the polymeric syntheses and the influence of the casting conditions on the gas separation properties must be known before a meaningful discussion on the influence of the macromolecular structure on the gas separation properties is justified. It is known that both permeability and selectivity may be sensitive towards these influences ${ }^{8,9}$.

\section{Influence of the poly-1,2,4-triazole batch}

Three batches of poly $[p, m$-phenylene-(4-phenyl)-1,2,4triazole], polymers 5,6 and 7 , were prepared to investigate the influence of the polymer synthesis on the gas separation properties. Bcsides the permeability and selectivity towards a carbon dioxide/methane gas mixture, the polymers were subjected to thermogravimetric analysis (t.g.a.). During a t.g.a. experiment unclosed groups undergo a cyclodehydration reaction, see Figure 3. The carbonyl and hydrazide groups capable of hydrogen bonding are converted into the less interacting 1,2,4-triazole and 1,3,4-oxadiazole groups. 


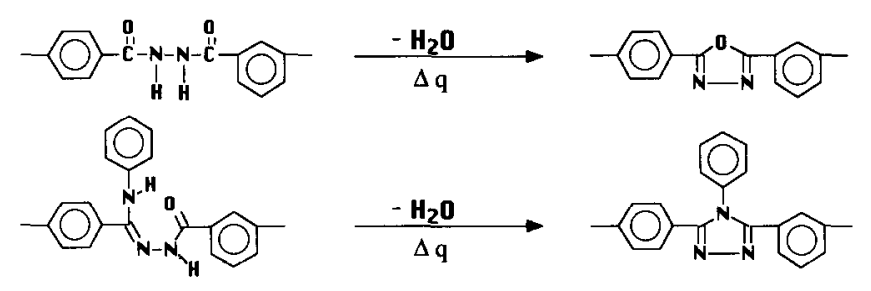

Figure 3 Cyclodehydration reaction of unclosed 1,3,4-oxadiazole and 1,2,4-triazole groups

The weight loss due to the formation of water caused by the cyclodehydration of unclosed groups is represented in Table 1. It is shown that the permeability increases with decreasing weight loss, and with the decreasing number of unreacted 1,2,4-triazole groups. Poly-1,2,4triazoles 5, 6 and 7 are prepared from a polyhydrazide precursor polymer (16) which has the maximum amount of hydrazide groups capable of hydrogen bonding, resulting in increased intermolecular interactions opposing easy passage of gas molecules. This results in low permeability values comparable to those found for polyamides. The polyhydrazide will be discussed later; it has an extremely low permeability for $\mathrm{CO}_{2}$ of 0.05 Barrer, comparable to the values found for Nylon- 6 and Nylon-6,6 of 0.1 and 0.07 Barrer, respcctively ${ }^{10}$. The latter two polymers also exhibit strong hydrogen bonding. The poly[ $p$-, $m$-phenylene-(4-phenyl)-1,2,4-triazole] studied by Gebben et al..$^{3}$ is also included in Table 1 . The gas separation properties of this polymer were determined under slightly different conditions.

Table 1 Gas separation properties of poly $[p-, m$-phenylene- (4phenyl) -1,2,4-triazole]s for a carbon dioxide/methane gas mixture as a function of the percentage weight loss due to unreacted 1,2,4-triazole groups

\begin{tabular}{|lllll|}
\hline Poly-1,2,4-triazole & $\begin{array}{l}P_{\mathrm{CO}_{2}} \\
\text { (Barrer) }\end{array}$ & $\alpha_{\mathrm{CO}_{2} / \mathrm{CH}_{4}}$ & $\begin{array}{l}\Delta w^{a} \\
(w t \%)\end{array}$ & $\begin{array}{l}T_{\mathrm{g}} \\
\left({ }^{\circ} \mathrm{C}\right)\end{array}$ \\
\hline $\mathrm{TIPT}^{b}$ (ref. 3) & 8.9 & 63 & $<1$ & 270 \\
$\mathrm{PT}-\mathrm{p} / \mathrm{m}-1$ & 5.8 & 47 & 2.07 & 264 \\
$\mathrm{PT}-\mathrm{p} / \mathrm{m}-2$ & 7.1 & 50 & 1.65 & 267 \\
PT-p/m-3 & 5.9 & 51 & 1.82 & 261 \\
\hline
\end{tabular}

${ }^{a}$ The maximum possible weight loss starting from the corresponding poly $(p-, m$-phenylene hydrazide $)$ is $11.1 \mathrm{wt} \%$

$b$ Measured using a pressure difference of 3 bar and a gas mixture consisting of 20 vol\% carbon dioxide and 80 vol\% methane

\section{Influence of the casting conditions}

Since it is known that permeability and selectivity can be sensitive to the casting conditions applied ${ }^{8}$, the influence of the membrane thickness and the evaporation temperature of formic acid and an additional heat treatment, to remove residual solvent, on the gas separation properties of $\mathrm{PT}-\mathrm{p} / \mathrm{m}-1$ were studied.

One casting solution of PT-p/m-1 was prepared from which four membranes were cast using casting knives with slit heights of $0.5 \mathrm{~mm}$ (2 samples) and $0.2 \mathrm{~mm} \mathrm{(2}$ samples). The casting solvent of two membranes with different casting thicknesses was evaporated at $80^{\circ} \mathrm{C}$ and the casting solvent of the other two was evaporated at room temperature, see Table 2.

After evaporation, the permeability and selectivity of the membranes for carbon dioxide in a carbon dioxide/methane gas mixture $(25 / 75$ vol\%) were determined continuously for 7 days. During this period the membranes were continuously exposed to a feed pressure of 6 bar and a vacuum at the downstream side of the membrane. Subsequently the membranes were subjected to a heat treatment at $150^{\circ} \mathrm{C}$ in a vacuum for at least $24 \mathrm{~h}$ after which the permeability and selectivity were measured ayain for the carbon dioxide/methane gas mixture. The results are summarized in Table 2. Besides carbon dioxide and methane, the permeabilities for oxygen and nitrogen were also measured, but as single gases and after the additional heat treatment (see Table 3).

Before the heat treatment, permeabilities of 12 to 14.2 Barrer for carbon dioxide were found after 1 day. In the course of the first day, high selectivities, well above 50 , were observed since only small concentrations of the slower permeating species, methane, are found during this non-steady situation. From day one to day seven the selectivities remained almost constant. The permeability of the as-cast membranes decreased in time, as can be seen from Table 2. After the heat treatment, values for the permeability were lower and constant in time. The time dependence of permeability and selectivity of PT-p/m-1-D before and after the heat treatment is shown in Figure 4. The decrease in permeability with time is representative for all membranes.

IR measurements show a strong absorption peak at $3400 \mathrm{~cm}^{-1}$ in the as-cast membranes indicating residual water and formic acid. (The absorption peaks of water and formic acid overlap to a large extent in the IR spectrum.)

Table 2 Variation of gas separation properties of polytriazole (PT-p/m-1) membranes with time, before and after heat treatment at $150^{\circ} \mathrm{C}$ in vacuum

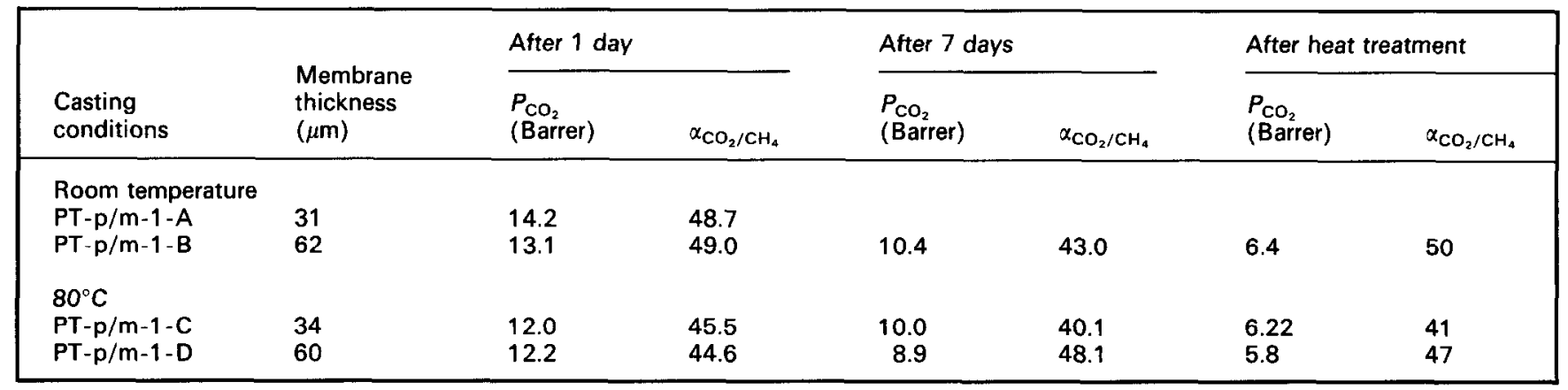


Table 3 Gas separation properties of poly-1,2,4-triazole, polyhydrazide and poly-1,3,4-oxadiazole membranes

\begin{tabular}{|c|c|c|c|c|c|c|c|c|}
\hline Polymer & $\begin{array}{l}P_{\text {co, }} \\
\text { (Barrer) }\end{array}$ & $\alpha_{\mathrm{CO}_{2} / \mathrm{CH}_{4}}$ & $\begin{array}{l}P_{\mathrm{O}_{2}} \\
\text { (Barrer) }\end{array}$ & $\begin{array}{l}P_{N_{2}} \\
\text { (Barrer) }\end{array}$ & $\begin{array}{l}\alpha_{\mathrm{O}_{2} / \mathrm{N}_{2}} \\
=\end{array}$ & $\begin{array}{l}T_{g}^{a} \\
\left({ }^{\circ} \mathrm{C}\right)\end{array}$ & $\begin{array}{l}\text { Density } \\
\left(\mathrm{g} \mathrm{cm}^{-3}\right)\end{array}$ & $\begin{array}{l}V_{f} \\
\left(=\left(V-1.3 V_{w}\right) / M\right) \\
\left(\mathrm{cm}^{3} \mathrm{~g}^{-1}\right)\end{array}$ \\
\hline $\begin{array}{ll}1 & \text { PT-0/100 } \\
2 & \text { PT-25/75 } \\
3 & \text { PT-50/50 } \\
4 & \text { PT-75/25-1 } \\
& \text { PT-75/25-2 }\end{array}$ & $\begin{array}{r}2.7 \\
3.3 \\
6.7 \\
10.1 \\
12.6\end{array}$ & $\begin{array}{l}55 \\
49 \\
50 \\
50 \\
47\end{array}$ & $\begin{array}{l}0.52 \\
0.59 \\
1.17 \\
1.46 \\
2.00\end{array}$ & $\begin{array}{l}0.09 \\
0.10 \\
0.18 \\
0.23 \\
0.30\end{array}$ & $\begin{array}{l}5.8 \\
5.9 \\
6.5 \\
6.3 \\
6.7\end{array}$ & $\begin{array}{l}242 \\
257 \\
279 \\
319 \\
319\end{array}$ & $\begin{array}{l}1.20 \\
1.20 \\
1.22 \\
1.25 \\
1.25\end{array}$ & $\begin{array}{l}0.0956 \\
0.0956 \\
0.0819 \\
0.0622 \\
0.0622\end{array}$ \\
\hline $\begin{array}{ll}5 & \mathrm{PT}-\mathrm{p} / \mathrm{m}-1 \\
6 & \mathrm{PT}-\mathrm{p} / \mathrm{m}-2 \\
7 & \mathrm{PT}-\mathrm{p} / \mathrm{m}-3\end{array}$ & $\begin{array}{l}5.8 \\
7.1 \\
5.9\end{array}$ & $\begin{array}{l}47 \\
50 \\
51\end{array}$ & 0.99 & 0.15 & 6.6 & $\begin{array}{l}264 \\
267 \\
261\end{array}$ & $\begin{array}{l}1.21 \\
1.21 \\
1.21\end{array}$ & $\begin{array}{l}0.0901 \\
0.0860 \\
0.0860\end{array}$ \\
\hline $\begin{array}{rr}8 & \text { PT-p } / m-25 \mathrm{Cl} \\
9 & \text { PT-p/m-50Cl } \\
10 & \text { PT-p } / m-75 \mathrm{Cl} \\
11 & \text { PT-p } / m-100 \mathrm{Cl}\end{array}$ & $\begin{array}{l}8.5 \\
6.8 \\
6.8 \\
6.6\end{array}$ & $\begin{array}{l}46 \\
46 \\
46 \\
42\end{array}$ & $\begin{array}{l}1.43 \\
1.11 \\
1.32 \\
1.21\end{array}$ & $\begin{array}{l}0.22 \\
0.17 \\
0.20 \\
0.18\end{array}$ & $\begin{array}{l}6.5 \\
6.5 \\
6.6 \\
6.7\end{array}$ & $\begin{array}{l}271 \\
269 \\
271 \\
274\end{array}$ & $\begin{array}{l}1.24 \\
1.26 \\
1.26 \\
1.31\end{array}$ & $\begin{array}{l}0.0796 \\
0.0819 \\
0.0917 \\
0.0718\end{array}$ \\
\hline $\begin{array}{l}12 \mathrm{PT}-\mathrm{p} / \mathrm{m}-25 \mathrm{~F} \\
13 \mathrm{PT}-\mathrm{p} / \mathrm{m}-50 \mathrm{~F} \\
14 \mathrm{PT}-\mathrm{p} / \mathrm{m}-100 \mathrm{~F}^{b}\end{array}$ & $\begin{array}{l}5.8 \\
8.0\end{array}$ & $\begin{array}{l}41 \\
47\end{array}$ & $\begin{array}{l}1.11 \\
1.53\end{array}$ & $\begin{array}{l}0.18 \\
0.22\end{array}$ & $\begin{array}{l}6.2 \\
7.0\end{array}$ & $\begin{array}{l}257 \\
269 \\
276\end{array}$ & $\begin{array}{l}1.26 \\
1.27 \\
1.30\end{array}$ & $\begin{array}{l}0.0647 \\
0.0669 \\
0.0646\end{array}$ \\
\hline $\begin{array}{rl}15 & \mathrm{PT}-\mathrm{p} / \mathrm{m}-\mathrm{Me} \\
16 & \mathrm{PH}-1 \\
17 & \mathrm{TI}-\mathrm{POD} \\
18 \mathrm{cCH} & \mathrm{cHOD}-1 \\
& \text { tCH-POD-2 } \\
& \text { (c+t)CH-POD-3 } \\
19 & \mathrm{PIDA}-\mathrm{POD} \\
20 & \mathrm{HF}-\mathrm{POD}-1 \\
& \mathrm{HF}-\mathrm{POD}-2 \\
21 & \mathrm{DPE}-\mathrm{POD}-1 \\
& \text { DPE-POD-2 } \\
22 & \mathrm{HF} / \mathrm{DPE}-\mathrm{POD}\end{array}$ & $\begin{array}{l}13.0 \\
0.05 \\
0.3 \\
0.2 \\
0.5 \\
0.2 \\
93.0 \\
78.0 \\
84.0 \\
0.3 \\
0.5 \\
5.0\end{array}$ & $\begin{array}{r}c^{38} \\
45 \\
27 \\
28 \\
23 \\
26 \\
28 \\
26 \\
168 \\
120 \\
28\end{array}$ & $\begin{array}{l}2.21 \\
c \\
c \\
c \\
c \\
c \\
17.1 \\
20.0 \\
c \\
c\end{array}$ & $\begin{array}{l}0.35 \\
c \\
c \\
c \\
c \\
c \\
3.3 \\
4.0 \\
c \\
c\end{array}$ & $\begin{array}{l}6.3 \\
c \\
c \\
c \\
c \\
c \\
5.2 \\
5.0 \\
c \\
c\end{array}$ & $\begin{array}{l}256 \\
d \\
e \\
179 \\
179 \\
180 \\
300 \\
282 \\
287 \\
333 \\
306 \\
339\end{array}$ & $\begin{array}{l}1.15 \\
1.43 \\
1.38 \\
1.21 \\
1.21 \\
1.21 \\
1.04 \\
1.36 \\
1.36 \\
1.45 \\
1.45 \\
1.45\end{array}$ & $\begin{array}{l}0.1098 \\
0.0610 \\
0.0342 \\
0.0898 \\
0.0898 \\
0.0898 \\
0.2066 \\
0.1109 \\
0.1109 \\
t \\
t \\
0.0748\end{array}$ \\
\hline
\end{tabular}

${ }^{2}$ Glass transition temperatures were determined using d.s.c. techniques except for PT-75/25-1 and PT-75/25-2; their $T_{\mathrm{g}}$ was determined using a torsion pendulum ${ }^{4}$

$\mathrm{PT}-\mathrm{p} / \mathrm{m}-100 \mathrm{~F}$ films were too brittle to allow permeation experiments

${ }^{c}$ Methane, oxygen and nitrogen permeabilities were too low to allow an accurate measurement

${ }^{d}$ The glass transition temperature of polyhydrazide cannot be determined directly; Gebben et al. ${ }^{11}$ have obtained a glass transition of $278^{\circ} \mathrm{C}$ upon extrapolation

- No $T_{g}$ detected using d.s.c. techniques ${ }^{4}$

${ }^{f}$ See text for discussion

The presence of water in the membrane may be caused by the presence of water in formic acid, up to $4 \%$, or by absorption of humidity during membrane formation. T.g.a. experiments showed that a dried and subsequently re-equilibrated poly-1,2,4-triazole membrane may contain up to $3 \%$ water. The intensity of the peak at $3400 \mathrm{~cm}^{-1}$ was lowered during the permeation experiment because both water and formic acid were evaporated from the membrane due to the vacuum at the permeate side of the membrane.

The peak at $3400 \mathrm{~cm}^{-1}$ vanishes completely after the heat treatment at $150^{\circ} \mathrm{C}$ in vacuum. After this heat treatment the membranes become more brittle and upon handling cracks are easily introduced resulting in leaky membranes. This indicates that water and/or residual formic acid acts as a plasticizer. During a permeation experiment the solvents or plasticizers are removed from the membrane because of the vacuum on the permeate side of the membrane. In Figure $4 b$ the decrease in permeability is plotted versus the logarithm of time. After heat treatment, all residual low-molecular-weight components are removed from the membrane and a permeability of 5.8 Barrer is found. In Figure $4 b$ it can be seen from extrapolation of the permeability of the non-heat-treated membrane to the final value of 5.8 Barrer that all residual solvent will be extracted from the membrane after approximately $1500 \mathrm{~h}$.

After the heat treatment the permeabilities of oxygen and nitrogen were also determined, being 0.99 and 0.15 respectivcly, resulting in an idcal selectivity of 6.6 .

When the membranes are exposed to air they take up moisture and the peak at $3400 \mathrm{~cm}^{-1}$ appears again in the IR spectrum. In addition to residual solvents, water is able to act as a plasticizer for polymers like polyvinyl alcohol, cellulose acetate and cellophane ${ }^{11}$. After exposure of a heat-treated membrane to the atmosphere for 3 months, equilibrium sorption of water is assumed and a carbon dioxide permeability of 6.4 and a carbon dioxide/methane selectivity of $43-45$ was found. This indicates that residual formic acid and not water must have acted as a plasticizer, causing the initial high permeabilities.

In order to explain plasticization effects, the free volume theory has been proposed in the literature ${ }^{12}$. During membrane formation, the volume available to the macromolecules is decreased due to the evaporation of the solvent. Residual solvent not evaporated during this process will result in an increased free volume and an increased chain mobility permitting a higher permeability. The polymer matrix compacts in the course of time upon the extraction of the residual solvent, resulting in a decreased free volume, reduced chain mobility and permeability. Besides the change in permeability, the mechanical properties also change resulting in an increase in brittleness upon the heat treatment at $150^{\circ} \mathrm{C}$ in vacuum. 

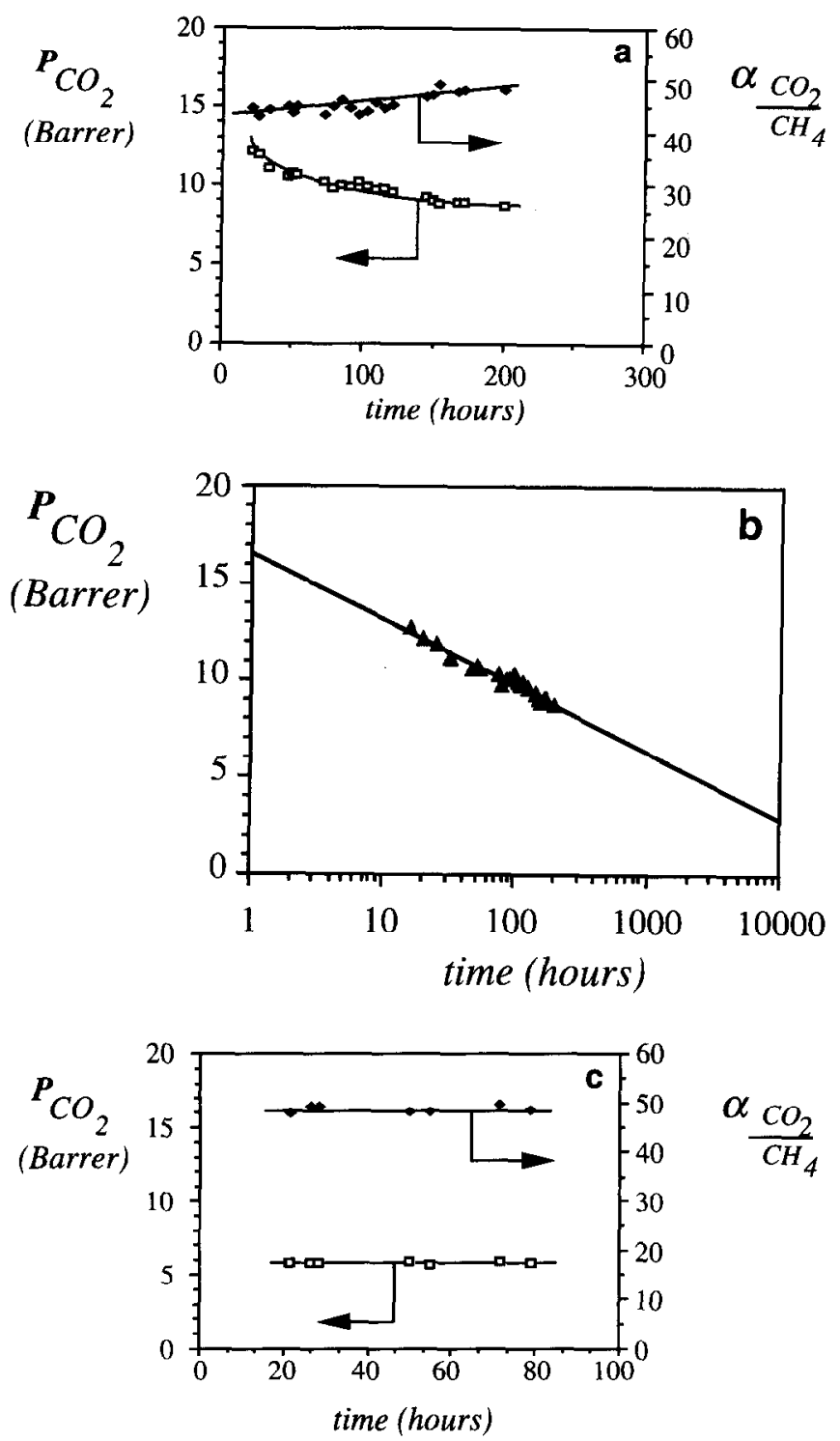

Figure 4 Influence of residual solvent on the permeability and the selectivity of a PT-p/m-1 membrane freshly prepared without an additional heat treatment (a). Permeability plotted vs. the logarithm of time (b) and permeability and selectivity after an additional heat treatment in vacuum at $150^{\circ} \mathrm{C}$ for $24 \mathrm{~h}$ (c)

One can conclude that the inherent values for permeability and selectivity are found after the heat treatment when all residual formic acid has been removed and the polymer film has attained its relaxed state. No significant differences were found between the permeability and selectivity values of thick and thin membranes after the heat treatment. Also the temperature of evaporation did not have a measurable effect on the inherent values of permeability and selectivity.

Thus, in order to be able to compare the values for the permeability and selectivity of different poly-1,2,4triazole membranes, the membranes must be completely free of residual formic acid. It was also found that the gas separation properties of $\mathrm{PT}-\mathrm{p} / \mathrm{m}-1$ membranes did not depend on the concentration of the original casting solution.

\section{Influence of the feed composition}

The permeability and selectivity values of poly-1,3,4oxadiazole, poly-1,2,4-triazole and polyhydrazide mem-

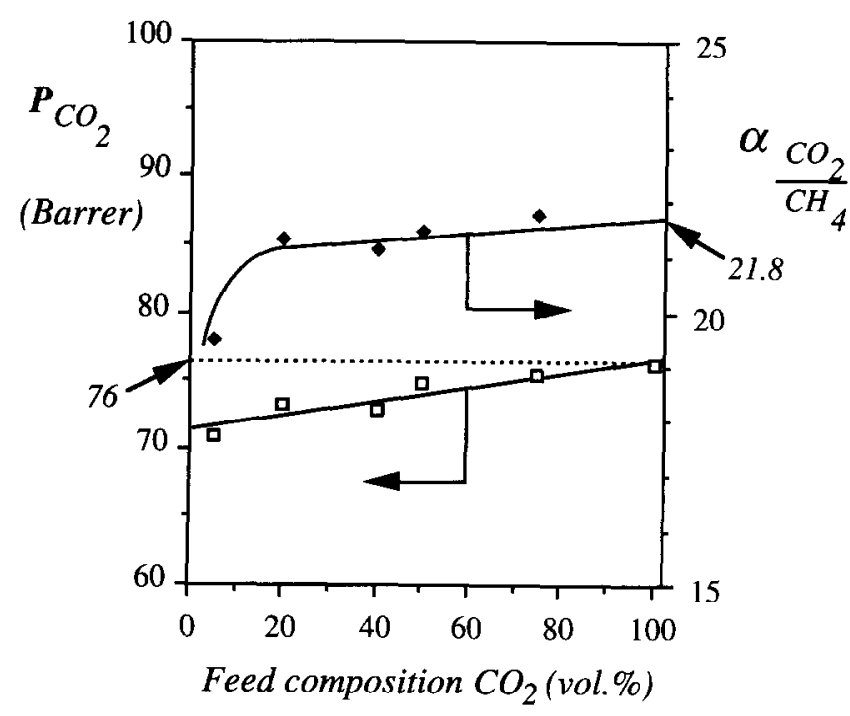

Figure 5 Influence of the carbon dioxide feed composition on permeability and selectivity for a PIDA-POD membrane at 6 Bar

branes were determined using oxygen and nitrogen as pure gases while for carbon dioxide and methane a gas mixture consisting of $25 \mathrm{vol} \%$ carbon dioxide and $25 \mathrm{vol} \%$ methane was used. The feed composition will, however, have its influence on the permeability and selectivity values ${ }^{13,14}$

In Figure 5, the influence of the carbon dioxide feed concentration on the membrane performance of a PIDA-POD membrane is represented. Both carbon dioxide permeability and selectivity increase a little with an increasing carbon dioxide feed concentration. On extrapolation to a feed composition of pure carbon dioxide, a selectivity of 21.8 is obtained. The methane permeability in the case of a feed composition consisting of pure methane was found to be 3.42 Barrer while for pure carbon dioxide a permeability of 76 Barrer was found. This results in an ideal selectivity using pure gas permeabilities of carbon dioxide and methane of 22.2 . The selectivity found using a gas mixture of $25 \mathrm{vol} \%$ carbon dioxide and $75 \mathrm{vol} \%$ methane yields somewhat lower values for both permeability and selectivity than would be obtained for single gases. Figure 5 shows that the faster permeating gas, carbon dioxide, is slowed down to some extent by the slower permeating methane.

This experiment was carried out with an 8-month-old membrane. The permeability and selectivities reported here are somewhat lower than those of freshly prepared PIDA-POD membranes, see Table 3. We assume that ageing effects are responsible for the decreased permeability.

\section{Influence of the macromolecular structure}

\section{Permeability and selectivity}

The main objective of the present study is to investigate the relationship between the macromolecular structure, the resulting physical properties and the gas separation properties of polyhydrazide, poly-1,3,4-oxadiazole and poly-1,2,4-triazole membranes. Various functional groups were incorporated into these related polymers (see Figure 1) to study their influence on the gas separation properties.

The two important characteristics of a gas separation membrane material are its permeability and selectivity. 


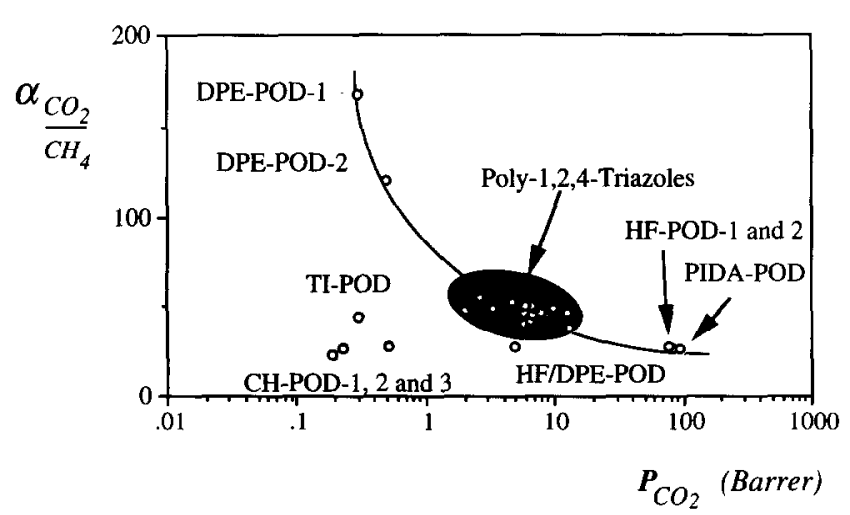

Figure 6 Permeability/selectivity curve for the poly-1,2,4-triazole and poly-1,3,4-oxadiazole membranes

In Figure 6 permeability is plotted versus selectivity of the polymers for a carbon dioxide/methane gas mixture $(25 / 75 \mathrm{v} / \mathrm{v})$. The data are also represented in Table 3. As can be seen from Figure 6, the typical trade-off between selectivity and permeability is found. Introducing a hexafluor unit into the backbone of a poly-1,3,4oxadiazole gives a polymer with a high permeability typically found for polymers containing this group, like polyimides $^{1,14}$ and polycarbonates ${ }^{15}$. Even higher permeabilities were found for PIDA-POD. This polymer contains the bulky and asymmetrical 1,1,3-trimethyl-3phenylindane moiety also found in Ciba-Geigy's 'XU-218'.

The extreme in both permeability and selectivity in comparison with HF-POD and PIDA-POD is DPEPOD. This poly-1,3,4-oxadiazole exhibits a low permeability and an extremely high permeability. Other polymers also containing this group like Kapton ${ }^{\mathbb{B}}$ and 6FDA-ODA ${ }^{16}$, see Figure 7, also exhibit higher selectivities in comparison with corresponding polymers not containing this group. The high selectivity of Kapton $^{(\mathbb{R})}$ is thought to originate from the high concentration of carbonyl groups in this polymer ${ }^{17}$. However, in the case of DPE-POD these carbonyl groups are not present although this polymer exhibits a high selectivity meaning that the impressive selectivity must be due to the diphenyl ether structure being a part of the main chain.

The low permeability of DPE-containing polymers is probably due to the relatively efficient packing of DPE-POD caused by its flexiblc ether linkage. Chern et al. ${ }^{16}$ have related the carbon dioxide/methane selectivity of a number of gas separation membrane materials to the solubility parameters of these polymers. A similar study is under way in our laboratory and the results will be reported in due course.

Two batches of DPE-POD and HF-POD were prepared and the reproducibility of the gas separation data is good, see Table 3. The large difference in selectivity values found for the two DPE-POD batches is caused by a relatively large impact of a small difference in methane permeability.

Polymers with a completely aromatic backbone are located on the hyperbolic line in Figure 6. The alicyclic
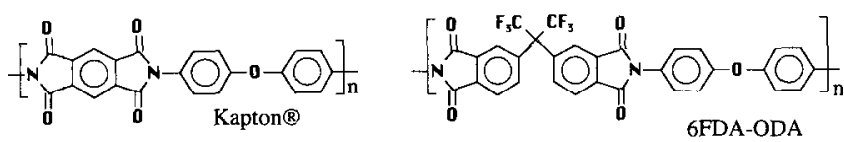

Figure 7 Chemical structures of two DPE-containing polymers
CH-PODs deviate which is clearly due to their flexible aliphatic cyclohexane rings. Three batches of $\mathrm{CH}-\mathrm{POD}$ were prepared (see Table 3), using pure cis- and trans-cyclohexane dicarboxylic acids and a mixture of both isomers as monomers.

Using d.s.c., t.g.a. and i.r. techniques it was found that the three polymer batches were identical ${ }^{5,18}$; this must be due to a conversion in the acidic reaction medium of the cis-isomer into the more stable trans-isomer. This implies that the differences in permeabilities as found here must be due to minor configurational differences or must lie within experimental error.

The high selectivities of the completely aromatic and rigid poly-1,3,4-oxadiazoles and poly-1,2,4-triazoles are believed to originate from their high chain rigidity and are also indicated by their high glass transition temperatures. These polymers are believed to behave as 'molecular sieves' generally exhibiting high diffusivity selectivities ${ }^{19}$ based on their ability to discriminate more effectively between permeant sizes and shapes.

\section{Permeability, diffusivity and solubility}

Permeability is considered to be the product of diffusivity and solubility:

$P=D S$

where $P$ is the permeability for a given gas in $\mathrm{cm}^{3}(\mathrm{STP}) \mathrm{cm}$ $\mathrm{cm}^{-2} \mathrm{~s}^{-1} \mathrm{cmHg}^{-1}, D$ is the diffusion coefficient in $\mathrm{cm}^{2} \mathrm{~s}^{-1}$ and $S$ is the solubility in $\mathrm{cm}^{3}$ (STP) $\mathrm{cm}^{-3}$ $\mathrm{cmHg}^{-1}$.

The diffusion coefficient is calculated from a transient state permeation experiment revealing the time-lag $\Theta$. This equation can be derived from non-steadystate Fickian diffusion with a constant diffusion coefficient ${ }^{20,21}$ :

$D=l^{2} / 6 \Theta$

where $l$ is the membrane thickness. The permeability was determined from the slope of the time-lag curve following the transient state. Equations (4) and (5) allow the calculation of solubility coefficients. Detailed discussions on theory ${ }^{22}$ and measuring techniques ${ }^{6}$ have been reviewed, and are therefore not discussed in detail here. Permeability and diffusivity values for a number of polymers were obtained from time-lag experiments with a vacuum at the downstream side and 6 bar at the feed side using carbon dioxide as a single gas, see Figure 8 .

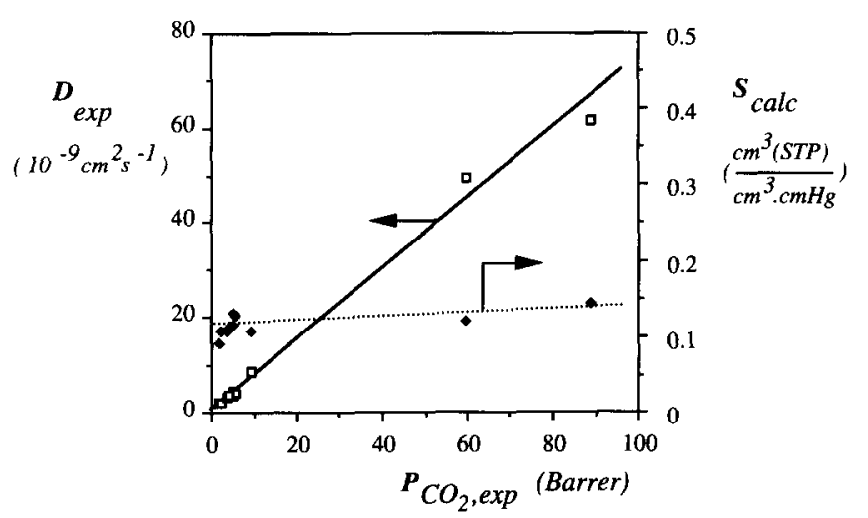

Figure 8. Experimental diffusivity and calculated solubility values for a number of poly-1,2,4-triazole and poly-1,3,4-oxadiazole membranes as a function of the measured permeability 
The carbon dioxide permeability values differ slightly from those represented in Figure 6 where a gas mixture consisting of $25 \mathrm{vol} \%$ carbon dioxide and $75 \mathrm{vol} \%$ methane is employed resulting in a partial pressure of 1.5 bar for carbon dioxide.

From Figure 8 it can be seen that the solubility remains almost constant while diffusivity increases linearly with permeability. This means that the increase in permeability is mainly caused by an increase in diffusivity.

\section{Influence of the $p$ - and $m$-phenylene content in} poly-1,2,4-triazoles

Several authors have investigated the influence of the ratio of $p-/ m$-phenylene groups on the gas separation properties of polyimides ${ }^{14}$, polyesters ${ }^{23}$, poly(phenolphthalein phthalate) $\mathrm{s}^{24}$, and poly(ethylene tere/ isophthalate) $\mathrm{s}^{25}$. In all cases the $p$-phenylene-substituted polymers exhibited higher permeabilities than the corresponding $m$-phenylene polymers.

Gebben et al. $^{3}$ have extensively investigated poly $[p$ $m$-phenylene-(4-phenyl)-1,2,4-triazole] for its gas separation properties. The $p$-phenylene and $m$-phenylene groups are incorporated in an alternating fashion in this polymer. However, what is the influence of the sequence of incorporation of these groups, viz. alternating versus random incorporation and what are the permeability and selectivity values for the two isomers, poly $[p$-phenylene(4-phenyl)-1,2,4-triazole] and poly[m-phenylene-(4-phenyl)-1,2,4-triazole]?

For the various $p-/ m$-isomers prepared, permeability and selectivity values together with the glass transition temperatures and densities are presented in Table 3. All of the poly-1,2,4-triazoles were soluble in formic acid, except for poly[ $p$-phenylene-(4-phenyl)-1,2,4-triazole] which was only soluble in concentrated sulfuric acid. No flexible membranes could, however, be prepared from the latter polymer solutions.

For the poly-1,2,4-triazoles, an increase in permeability was found with increasing $p$-phenylene content in the polymer backbone (see Figure 9). Selectivity remains almost constant for this series of isomers despite the increasing permeability. The increase in permeability is mainly due to an increasing diffusivity, the solubility is hardly changed. This could be expected since the chemical composition of the polymers, and thus the polymerpermeant interaction, is not changed at all.

A semi-logarithmic relation between permeability and $p$-phenylene content is observed. A similar dependence of permeability has been found by Schmidhauser and Longle ${ }^{26}$ for aromatic polycarbonates and by Barnabeo et al $^{27}$ for various random copolymers. The following relation has been proposed to describe the relation between permeability and polymer composition:

$\log P_{\mathrm{AB}}=X_{\mathrm{A}} \log P_{\mathrm{A}}+X_{\mathrm{B}} \log P_{\mathrm{B}}$

The relation allows calculation of the permeability of intermediate and homopolymers.

Upon extrapolation of permeability, diffusivity and solubility values for poly[p-phenylene-(4-phenyl)-1,2,4triazole] can be determined, see Figure 9. The permeability values for carbon dioxide, oxygen and nitrogen are 21,2.7 and 0.4 Barrer respectively. Selectivity is less dependent on the ratio of $p-/ m$-phenylene groups, and selectivities of 48 for carbon dioxide/methane and 6.8 for oxygen/nitrogen are found upon extrapolation.
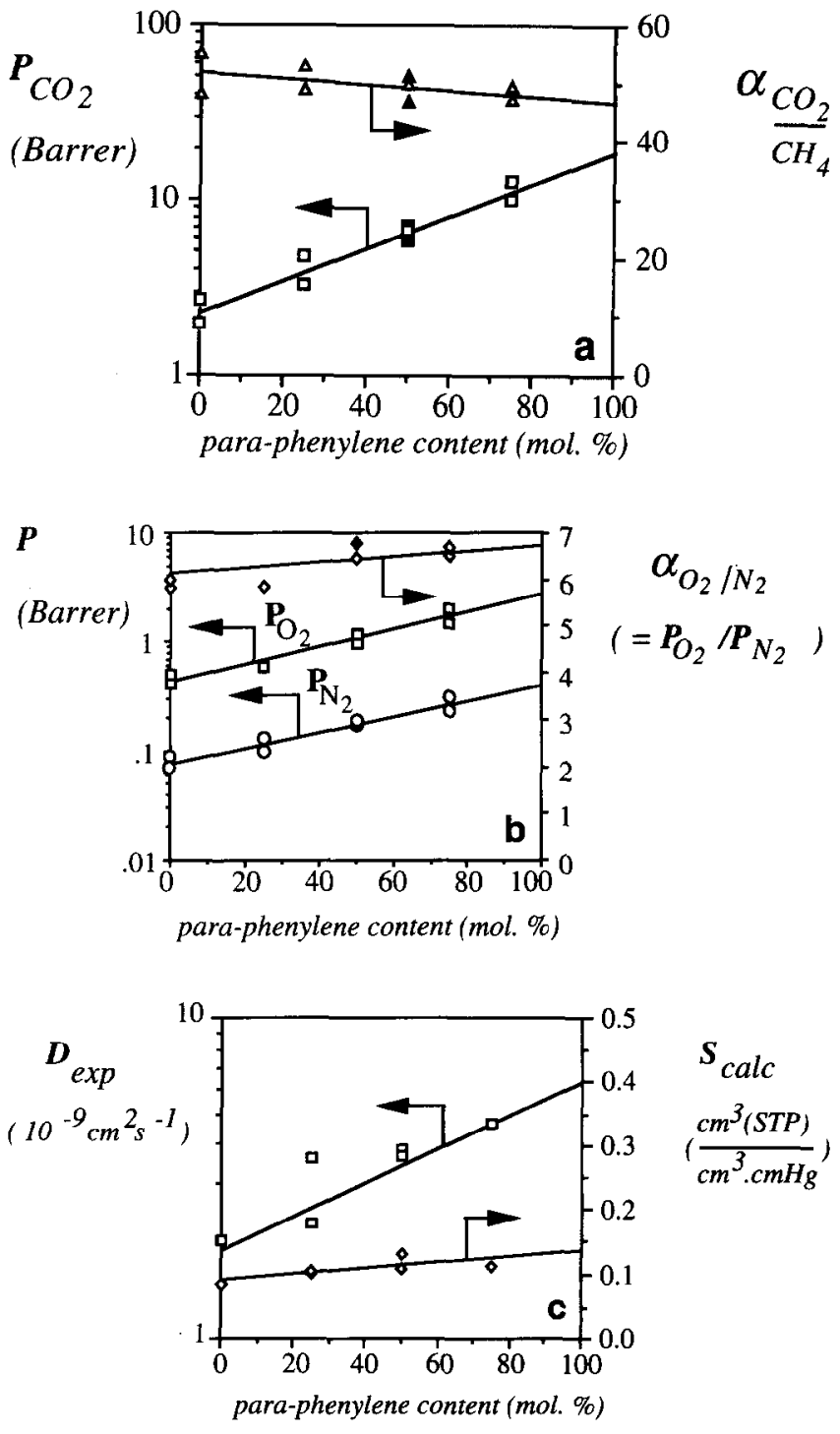

Figure 9 Permeability and selectivity values for alternating ( $\square$ A C) and random ( $\square \Delta O)$ poly $[\boldsymbol{p}, m$-phenylene (4-phenyl)1,2,4-triazole]s for a carbon dioxide/methane mixture (a), oxygen and nitrogen (b) as function of the $p$-phenylene content in the main chain. Carbon dioxide diffusivity and sorption as a function of the $p$-phenylene content in the main chain (c).

Besides the random copolymers the permeability and selectivity values of the alternating copolymers are also plotted in Figure 9. These values do not deviate significantly from those found for the random copolymers.

Considering these results and those of other authors ${ }^{23-25}$, we can conclude that an increasing permeability with increasing ratio of $p$-phenylene over its $m$-isomer is likely to be a general phenomenon. The increase in permeability was found to be mainly due to the increase in diffusivity which was also reported by Coleman and $\operatorname{Koros}^{14}$ for two isomeric $m$ - and $p$-connected fluorinated polyimides.

\section{Glass transition and free volume}

Like the permeability, the glass transition temperature for the $p$-phenylene polymer is higher than for the $m$-phenylene polymer. The density of the $p$-isomer is in all cases lower ${ }^{14,24,25}$. (No data on density and glass transition temperatures are reported by Schmidhauser and Longley ${ }^{23}$.) 
Sheu and Chern $^{24}$ have attributed the increase in permeability to the increasing free volume of the $p$-isomer caused by its lower density. Since these copolymers have the same van der Waals volume, a lower density results in a higher free volume. Differences in density are, however, very small. In our case the density increases with increasing $p$-phenylene content which seems to be in contradiction with the explanation of Sheu and Chern (see Table 3).

Other authors have attributed the increasing permeability to an increasing torsional mobility or "revolving door' effect of the $p$-phenylene group allowing passage of a gas molecule ${ }^{14}$, (see Figure 10). This rotation is not likely in the solid state in the case of the $m$-isomer since this would also require the rotation of the adjacent groups. Gillham and Gillham ${ }^{28}$ have shown by means of thermomechanical techniques on related polyimides that the $m$-isomer has indeed suppressed sub- $T_{\mathrm{g}}$ motions. These motions were also found by Light and Seymour ${ }^{25}$ for the $m$-connected polyester in comparison to the $p$-isomer. Several authors have speculated that these sub- $T_{\mathrm{g}}$ motions may be responsible for the higher gas permeability of the $p$-isomers because they would allow diffusional jumps to occur.

Dynamical mechanical analysis on these poly-1,2,4triazoles showed $\beta$-relaxations at $-113^{\circ} \mathrm{C}$ (recorded on a Myrenne torsion pendulum with a frequency of $1 \mathrm{~Hz}$ and a heating rate of $1.8^{\circ} \mathrm{C} \min ^{-1}$ ). Wc could, howcver, not observe distinct differences between the isomers. Recently, Schmidhauser and Longley ${ }^{26}$ have shown that this particular motion cannot be the rate limiting step. McHattie et al. ${ }^{9}$ studied the gas transport in various polysulfones and reported that the temperature of the peak maximum of the sub- $T_{\mathrm{g}}$ motions of various polysulfones is inversely related to their free volume. In other words, a higher free volume allows small scale motions at lower temperatures indicating that sub- $T_{\mathrm{g}}$ motions are a function of free volume. Lee ${ }^{29}$ has shown that permeability can be expressed as a function of the free volume. It seems that the (amount of) free volume is the rate-limiting factor for both sub- $T_{\mathrm{g}}$ motions and gas permeability. Although segmental motions may be necessary to allow the passage of a permeating gas molecule, the amount of free volume seems to be the controlling factor.

We therefore speculate that the increased permeability upon increased $p$-content is due to a difference in packing between the poly-1,2,4-triazole isomers resulting in a different free volume and a different distribution of free volume and we would like to follow the illustrative explanation of Dimarzio and $\mathrm{Gibbs}^{30}$ on the difference in the packing of rigid polymers versus flexible polymers.

All of the poly-1,2,4-triazole membranes were prepared by casting a polymer solution in formic acid onto a glass plate followed by evaporation of the solvent. During the
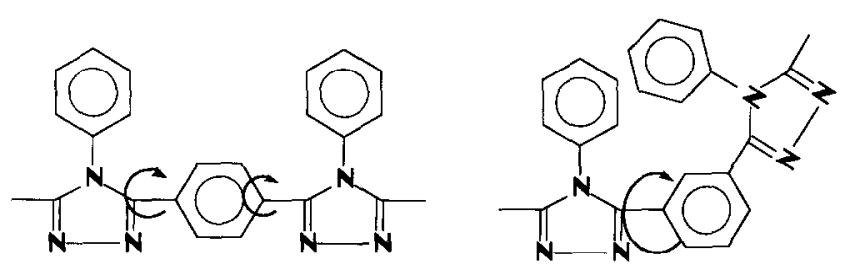

Figure 10 Chain segments of poly[p-phenylene-(4-phenyl)1,2,4-triazole $]$ and poly $[m$-phenylene-(4-phenyl)-1,2,4-triazole $]$ evaporation process the macromolecules approach each other. From entropy considerations it follows that during this process of polymer matrix formation, the macromolecules will try to occupy the space available as equally as possible, resulting in a narrow free-volume distribution. The only difference between the isomeric $m$ - and $p$-phenylene poly-1,2,4-triazoles is the extra axis of rotation available to the $m$-isomer through which it can change its conformation during membrane formation. The $p$-isomer is a rod-like macromolecule and rotation does not change its conformation to the same extent as in the case of the $m$-isomer, see Figure 10. An amorphous polymer matrix of the $p$-isomer can be compared to a heap of strands of uncooked spaghetti, requiring substantially more free volume than the more flexible $m$-isomer which can be compared to cooked spaghetti which will pack into a much tighter form during membrane formation ${ }^{30}$. This extra axis of rotation of the $m$-isomer, through which it can change its conformation during membrane formation, will yield a polymer matrix which has a much narrower free-volume distribution. The rigid $p$-isomer has a smaller number of possible conformations resulting in a smaller probability to achieve optimal relaxation of non-equilibrium free volume. This results in a larger free volume and a broader free-volume distribution and consequently a higher permeability. In macroscopic terms this difference is small as is indicated by the small differences in densities ${ }^{\mathbf{1 4 . 2 4 . 2 5}}$ and may be easily overshadowed by measuring inaccuracies. Since differences in densities are very small, these results should not be overinterpreted. Their reliability may be influenced by side-effects like polymer/solvent interactions in the density column or by residual impurities in the polymer matrix. Density measurements reveal an integrated determination of free volume. Of equal importance is the distribution of free volume since diffusion is assumed to take place only through holes with a minimal critical hole size, depending on the size of the permeant. This free volume distribution may be estimated using, for example, probe techniques ${ }^{31}$.

Gas transport is believed to be much more sensitive to subtle changes in the polymer matrix than other techniques, like density measurements, can reveal. A technique sensitive to the same conformational differences in the polymer matrix as gas diffusion of molecules is positron annihilation which has been studied extensively by Durgar'yan et $a .^{32}$. They reported an increased fraction of free volume with increasing glass transition temperature for various polymers. This behaviour was also found for the polymers studied; with increasing $p$-phenylene content the glass transition temperature and the permeability increase. Fritzsche et al. ${ }^{33}$ have prepared polysulfone hollow-fibre membranes using Lewis acid/ base solvent systems which resulted in an acceleration of the coagulation process. This results in membranes with an increased non-equilibrium free volume which is reflected by an increased glass transition temperature. Van Krevelen ${ }^{34}$ allows us to interpret this increase in free volume on the basis of the increase in glass transition temperature, as follows.

Thermal expansion below and above the glass transition temperature can be visualized using the concept of Simha and Boyer ${ }^{35}$, see Figure 11. Decreasing the temperature from the rubbery state results in a decreasing free volume above the glass transition temperature. Below the glass transition temperature, movements of only small 


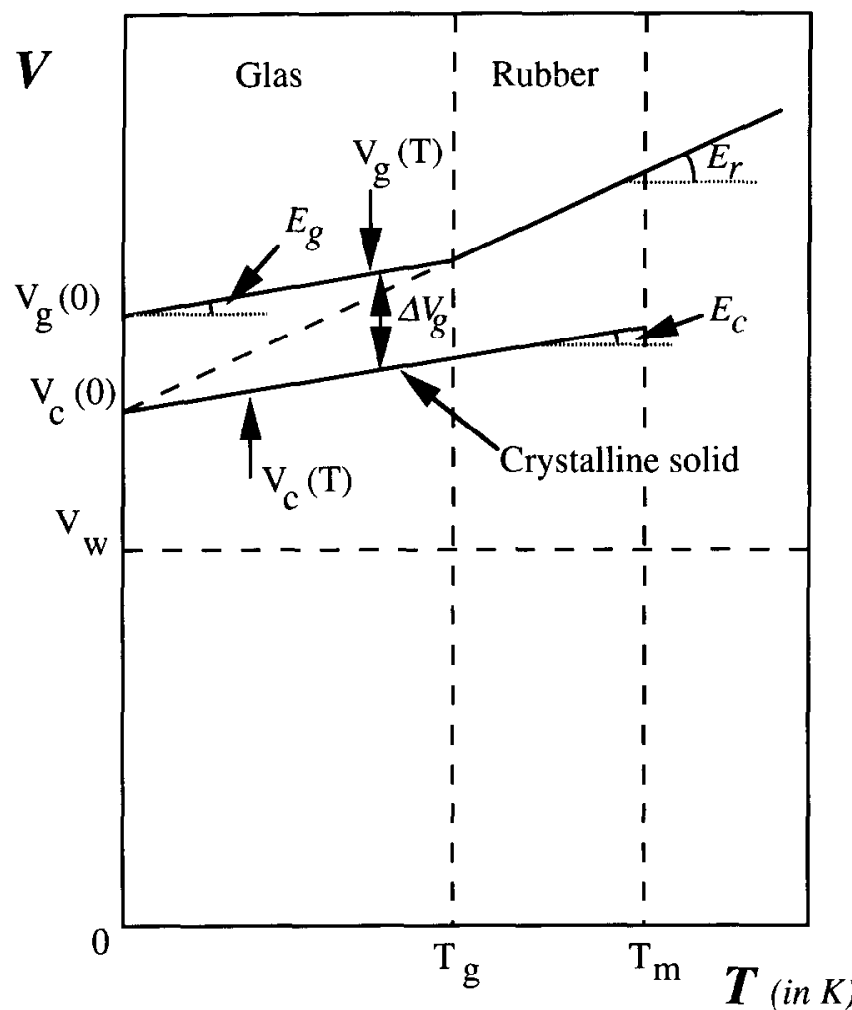

Figure 11 Thermal molar expansions of polymers in the rubbery state $\left(E_{\mathrm{r}}\right)$, glassy state $\left(E_{\mathrm{g}}\right)$ and crystalline state $\left(E_{\mathrm{c}}\right)\left(\Delta V_{\mathrm{g}}, V_{\mathrm{w}}, V_{\mathrm{g}}\right.$ and $V_{\mathrm{c}}$ are in $\left.\mathrm{cm}^{3} \mathrm{~mol}^{-1}\right)^{34,35}$

parts of the chain are possible and the non-equilibrium free volume is assumed to be constant in the glassy state as visualized in Figure 11.

Van Krevelen ${ }^{34}$ found that the molar thermal expansivities in the rubbery and glassy state $\left(E_{\mathrm{r}}\right.$ and $\left.E_{\mathrm{g}}\right)$ of most polymers is related to the van der Waals volume:

$$
\begin{aligned}
& E_{\mathrm{r}}=1.00 \times 10^{-3} V_{\mathrm{w}} \quad\left(\text { in } \mathrm{cm}^{3} \mathrm{~mol}^{-1} \mathrm{~K}^{-1}\right) \\
& E_{\mathrm{c}}=E_{\mathrm{g}}=0.45 \times 10^{-3} V_{\mathrm{w}} \quad\left(\text { in cm } \mathrm{mol}^{-1} \mathrm{~K}^{-1}\right)
\end{aligned}
$$

$E_{\mathrm{c}}$ stands for the expansion coefficient of the crystalline materials, or in the case of amorphous materials for the total solid including interstitial volume.

Since $\Delta V_{\mathrm{g}}$ is constant over the whole region below the glass transition temperature $T_{\mathrm{g}}$ :

$$
\Delta V_{\mathrm{g}}(0)=\Delta V_{\mathrm{g}}\left(T_{\mathrm{g}}\right)
$$

At $T_{\mathrm{g}}$ the molar volumes in the rubbery and glassy state are equal, see Figure 11 .

$V_{\mathrm{g}}(0)+E_{\mathrm{g}} T_{\mathrm{g}}=V_{\mathrm{c}}(0)+E_{\mathrm{r}} T_{\mathrm{g}}$

Thus,

$$
\begin{aligned}
\Delta V_{\mathrm{g}} & =V_{\mathrm{g}}(0)-V_{\mathrm{c}}(0)=\left(E_{\mathrm{r}}-E_{\mathrm{g}}\right) T_{\mathrm{g}} \\
& =(1.00-0.45) \times 10^{-3} V_{\mathrm{w}} T_{\mathrm{g}}=0.55 \times 10^{-3} V_{\mathrm{w}} T_{\mathrm{g}}
\end{aligned}
$$

In order to obtain the specific free volume, $\Delta V_{\mathrm{g}}$ is divided by the molecular weight $M$ :

$$
V_{\mathrm{f}}=\Delta V_{\mathrm{g}} / M \quad\left(\text { in } \mathrm{cm}^{3} \mathrm{~g}^{-1}\right)
$$

In Figure $12 a$ the specific free volume $V_{\mathrm{f}}$ defined by Equations (11) and (12) is plotted versus the percentage $p$-phenylene groups in the main chain. It can be seen that the specific free volume increases with increasing percentage of $p$-phenylene groups. The alternating poly-1,2,4-triazoles exhibit a somewhat lower specific free volume. This simple calculation allows us to estimate the specific free volume using $T_{\mathrm{g}}$ values instead of density measurements. This approach is believed to yield a more accurate approximation of the free volume for these closely related poly[ $p$-, $m$-phenylene-(4-phenyl)-1,2,4-triazole]s. In Figure $12 b$ the carbon dioxide permeability is plotted as a function of the free volume thus calculated. Polymers with high glass transition temperatures mostly exhibit high permeabilities which is due to the larger free volume as indicated by Equation (11).

\section{Influence of p-phenyl substitution in poly-1,2,4- triazoles}

Various pendent $p$-substituted phenyl groups in different ratios were incorporated onto the polymer backbone of alternating poly[ $p$-, $m$-phenylene-(4-phenyl)1,2,4-triazole], see Figure 1, and Table 3. The aim is to relate the change in gas separation properties to the change in steric and polar interactions caused by the incorporated specific group. A similar study for substituted polystyrenes has been carried out by Puleo et $a .^{36}$.

Compared to unmodified poly $[p-, m$-phenylene-(4phenyl)-1,2,4-triazole], incorporation of a methyl group
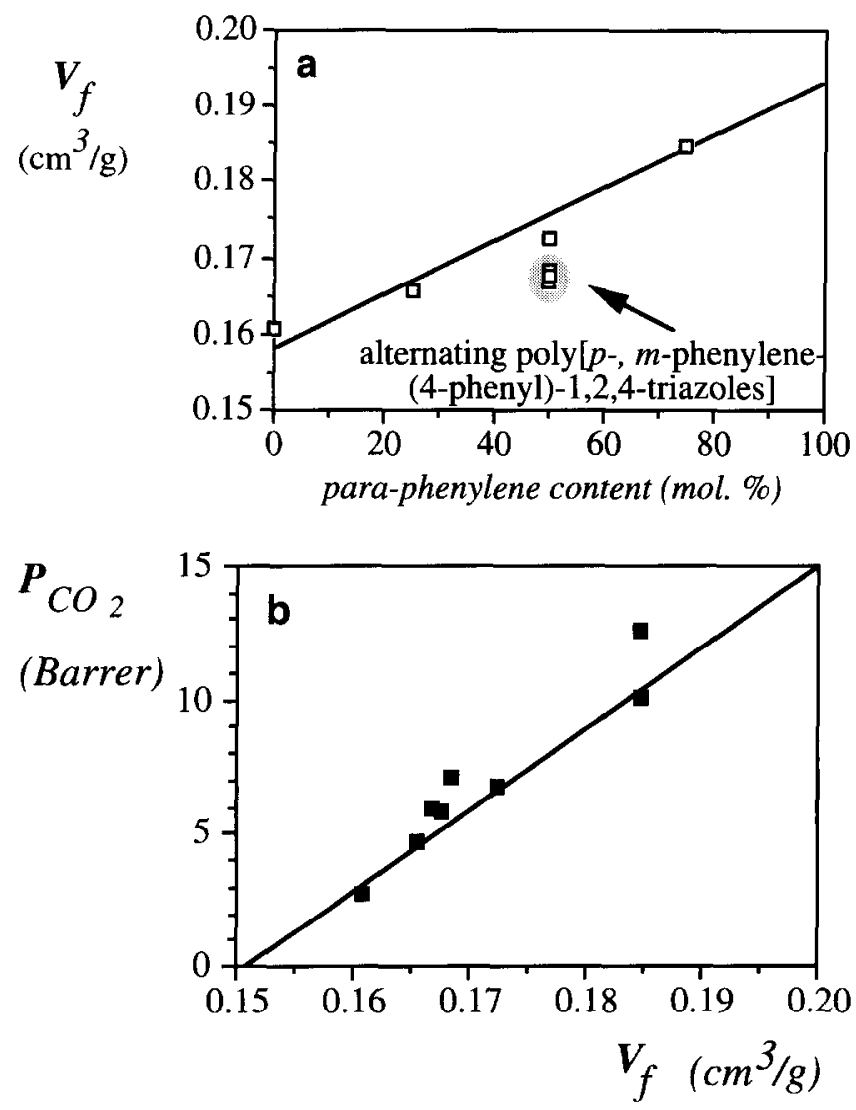

Figure 12 Free volume $\left(V_{f}\right)$ calculated using Equations (11) and (12) as a function of the $p$-phenylene content in the main chain (a) and permeability as a function of free volume for these series of isomeric poly $[p$-, $m$-phenylene(4-phenyl)-1,2,4-triazole $]$ s (b) $\left(V_{\mathrm{f}}\right.$ in $\left.\mathrm{cm}^{3} \mathrm{~g}^{-1}\right)$ 
results in an increased permeability whereas the selectivity slightly decreases. This increase in permeability is due to an increased free volume, see Table 3. The methyl groups obviously reduce the chain packing efficiency.

The halogen-substituted poly-1,2,4-triazoles all have a lower free volume than the unmodified ones. Due to the increased polarity, cohesive forces are increased resulting in a more densely packed polymer matrix with a lower free volume. Since fluorine is more electronegative than chlorine, higher intermolecular forces are responsible for the lower free volume of the fluorine-substituted poly-1,2,4-triazoles.

However, variations in permeability due to these modifications are small. Larger pendent groups may increase permeability more dramatically, but the possibility of incorporating larger structures, like biphenylic structures, appears to be limited ${ }^{5}$.

\section{Relation between permeability and free volume of the polymers studied}

The free volume model describing gas permeability as a function of the polymer free volume has recently received much attention ${ }^{37-39}$. Lee $^{29}$ was the first to correlate the permeability of polymers with their specific free volume. For this purpose the hole theory of diffusion was adopted, postulating that the rate of diffusion depends on the number and size distribution of existing holes in the polymer matrix ${ }^{40}$. This theory assumes that diffusion of a gas only then takes place if the local specific volume in the polymer matrix exceeds a minimum value, allowing diffusion of a gas molecule. The free volume is defined as

$V_{\mathrm{f}}=V-V_{0}$

where $V$ is the polymer specific volume and $V_{0}$ is the volume occupied by the chains. The latter is the molar volume at $0 \mathrm{~K}$. This volume is assumed to be impermeable for diffusing gas molecules. Lee $^{29}$ calculated $V_{0}$ using the relation proposed by Bondi ${ }^{41}$ :

$V_{0}=1.3 V_{\mathrm{w}}$

The van der Waals volume $\left(V_{\mathrm{w}}\right)$ is calculated using a group contribution method. We have used the tabulation of Askadskii ${ }^{42}$ to calculate $V_{\mathrm{w}}$.
In the case of densely packed polymers the free volume will be small. In Equation (13), $V_{0}$ is subtracted from $V$, obtained through a density measurement and through a summation of group contributions, respectively. Subtraction of these large numbers yields a small value for $V_{\mathrm{f}}$ with a relative large error. For the DPE-POD polymers a negative value for $V_{\mathrm{f}}$ was obtained which is likely to be due to errors in the measured specific volume. On the other hand, the factor 1.3 is arbitrary and may not be justified in all cases. DPE-POD has flexible ether bonds probably allowing the polymers to pack more efficiently to such an extent that the factor 1.3 is not appropriate in this case. One may therefore conclude that $V-1.3 V_{w}$ offers an approximation of the free volume available for permeation but that it may in some cases be an oversimplification of the considered phenomena. In Table 3 the free volumes calculated are presented.

Lee $^{29}$ has shown that the permeability can be correlated with the specific free volume $V_{\mathrm{f}}$ using in $P=D S$ the following expression for $D$ :

$D=D_{0} \exp \left(-B / V_{\mathrm{f}}\right)$

This gives for $P$ :

$P=S D_{0} \exp \left(-B / V_{\mathrm{f}}\right)$

Since $S$ is practically constant in our case, see Figure 8 , Equation (16) can be written as

$P=A \exp \left(-B / V_{\mathrm{f}}\right)$

in which the parameters $A$ and $B$ depend on the type of gas. This simple free volume treatment allows a direct insight into the influence of the macromolecular structure on the gas transport properties.

In Figure 13 the carbon dioxide permeabilities are plotted versus the reciprocal $V_{\mathrm{f}}$ values. A linear dependency can be observed although there is much scattering, especially for CH-POD and $\mathrm{PH}$ which is attributed to their essentially different macromolecular structures. Whereas all the other polymers have a rigid aromatic backbone, $\mathrm{CH}-\mathrm{POD}$ and $\mathrm{PH}$ have a more flexible backbone. This probably enables these polymers to achieve a different packing compared to the other all-aromatic polymers. $\mathrm{CH}-\mathrm{POD}$ and $\mathrm{PH}$ can obviously

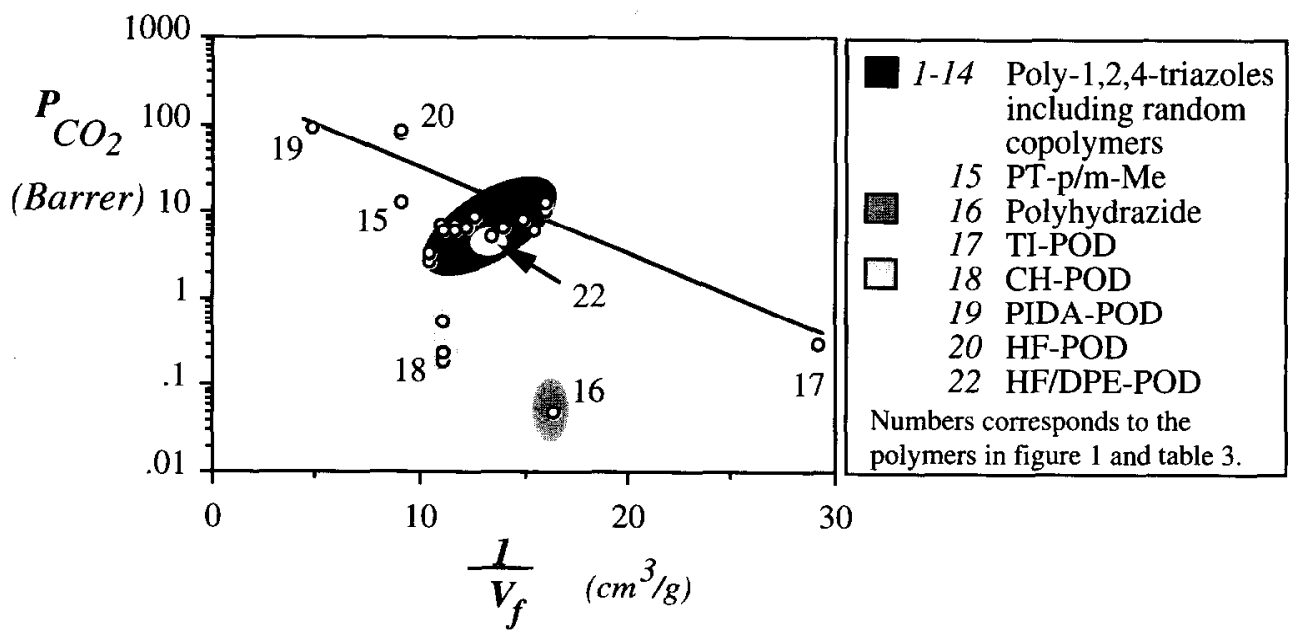

Figure 13 Carbon dioxide permeability as a function of the reciprocal free volume $V_{f}$ 
achieve a more optimal and thus a more narrow free volume distribution due to their flexible bonds. Schmidhauser and Longley ${ }^{26}$ also found decreased permeabilities upon incorporation of cyclohexane units in polycarbonates which was attributed to the ability of this moiety to adopt a sterically compact conformation. $\mathrm{PH}$ is capable of strong cohesive forces due to hydrogen bonding between amide and carbonyl groups making passagc of permeant molecules more difficult. A good correlation between permeability and reciprocal $V_{\mathrm{f}}$ values is obviously only obtained if intermolecular forces and chain flexibility or rigidity are comparable in magnitude ${ }^{43}$.

\section{Conclusions}

Poly-1,2,4-triazoles and poly-1,3,4-oxadiazoles are two interesting polymer families of new membrane materials for gas separation purposes. A wide variety of permeabilities and selectivities can be found for these two polymer families. Incorporating a diphenyl ether (DPE) moiety into the polymer backbone of a poly-1,3,4oxadiazole yields a polymer with a remarkable high selectivity. Incorporation of a hexafluor (HF) or phenyl indane (PIDA) unit results in poly-1,3,4-oxadiazoles with very high permeabilities in combination with reasonable selectivities.

The permeability of the poly-1,2,4-triazoles appears to depend on the amount of unclosed triazole groups; the highest permeabilities are to be found for the fully converted poly-1,2,4-triazole.

The casting conditions have no significant effect on the gas separation properties; however, residual formic acid may act as a plasticizer. Formic acid can be removed from the membrane by heat treatment at $150{ }^{\circ} \mathrm{C}$ for at least $24 \mathrm{~h}$.

The gas separation values are to a minor extent a function of the feed composition, and the permeabilities of single gases and the resulting ideal selectivity may deviate from permeability and selectivity values found for real gas mixtures.

The differences in permeability are in all cases due to differences in diffusivity; both may increase over several orders of magnitude while solubility hardly changes.

The permeability of polyhydrazide, poly-1,3,4-oxadiazole and poly-1,2,4-triazole membranes can be expressed as a function of their free volume. Permeability also increases with increasing $p$-phenylene content in the isomeric poly $[p-, m$-phenylene-(4-phenyl)-1,2,4-triazole $]$ s which is probably due to an increase in free volume available for permeation.

\section{Acknowledgements}

Akzo International Research is acknowledged for their financial support and CPNQ Brazil is acknowledged for the support of the research project of M.E.R. Sena.

\section{References}

1 Kim, T.H., Koros, W.J., Husk, G.R. and O'Brien, K.C. $J \mathrm{Membr}$ Sci (1988) 3745

2 Langsam, M., Anand, M. and Karwacki, E.J. Gas Sep Purif (1988) 2162

3 Gebben, B., Mulder, M.H.V. and Smolders, C.A. $J$ Membr Sci (1989) 4629
4 Hensema, E.R., Boom, J.P., Mulder, M.H.V. and Smolders, C.A. $J$ Polym Sci Polym Chem Ed (1994) 32513

5 Hensema, E.R., Sena, M.E.R., Mulder, M.H.V. and Smolders, C.A. $J$ Polym Sci Polym Chem Ed (1994) 32527

6 Felder, R.M. and Huvard, S.S. Methods of experimental physics Solid State Physics (Ed L. Marton), Vol 16, Academic Press, New York (1980) Chapter 17

7 Van't Hof, J.A. Wet spinning of asymmetric hollow fibre membranes for gas separation PhD Thesis University of Twente (1988)

8 Moe, M., Koros, W.J., Hoehn, H.H. and Husk, G.R. J Appl Polym Sci (1988) 361833

9 McHattie, J.S., Koros, W.J. and Paul, D.R. Polymer (1991) 32840

10 Bixler, H.J. and Sweeting, O.J. Barrier properties of polymer films The science and technology of polymer films (Ed O.J. Sweeting) Vol. 2, New York (1977) Chapter 1

11 Gebben, B., Mulder, M.H.V. and Smolders, C.A. J Polym Sci Polym Chem Ed (1988) 261757

12 Sears, J.K. and Touchette, N.W. Plasticizers Encycl Polym Sci Eng (Ed Kroschwitz), Vol. 18, Wiley, New York (1987) p. 111

13 Koros, W.J., Chern, R.T., Stannet, V.T. and Hopfenberg, H.B. J Polym Sci Polym Phys Ed (1981) 191513

14 Coleman, M.R. and Koros, W.J. J Membr Sci (1990) 50285

15 Hellums, M.W., Koros, W.J., Husk, G.R. and Paul, D.R. J Membr Sci (1989) 469

16 Chern, R.T., Koros, W.J., Hopfenberg, H.B. and Stannet, V.T. Material selection for membrane-based gas separations Materials Science of Synthetic Membranes (Ed D.R. Lloyd), ACS Symp. Ser., Vol. 269, Washington (1985) Chapter 2

17 Koros, W.J. J Polym Sci Polym Phys Ed (1985) 231611

18 Iwakura, Y., Uno, K. and Hara, S. Makromol Chem (1966) 95248

19 Stern, S.A., Shah, V.M. and Hardy, B.J. J. Polym Sci Polym Phys $E d(1987) 251263$

20 Crank, J Mathematics of diffusion Clarendon Press, Oxford (1975)

21 Mulder, M.H.V. Basic Principles of Membrane Technology Kluwer Academic, Dordrecht (1991)

22 Frisch, H.L. and Stern, S.A. Diffusion of small molecules in polymers CRC Crit Rev Solid State Mat Sci (1983) 11123

23 Schmidhauser, J.C. and Longley, K.L. Polym Prepr Am Chem Soc Div Polym Chem (1989) 3013

24 Sheu, F.R. and Chern, R.T. J. Polym Sci Polym Phys Ed (1989) 27 1121

25 Light, R.R. and Seymour, R.W. Polym Eng Sci (1982) 22857

26 Schmidhauser, J.C. and Longley, K.L. J. Appl Polym Sci (1990) 39 2083

27 Barnabeo, E.A., Creasy, W.S. and Robeson, L.M. J Polym Sci Polym Chem Ed (1975) 131979

28 Gillham, J.K. and Gillham, H.C. Polym Eng Sci (1973) 13447

29 Lee, W.M. Polym Eng Sci (1980) 2065

30 Dimarzio, E.A. and Gibbs, J.H. J. Polym Sci (1959) 40121

31 Victor, J.G. and Torkelson, J.M. Macromolecules (1987) 202241

32 Durgar'yan, S.G., Yampol'skii, Yu. P. and Plate, N.A. Russ Chem Rev (1988) 57549

33 Fritzsche, A.K., Kesting, R.E. and Murphy, M.K. J Membr Sci (1989) 46135

34 Van Krevelen, A.K. Properties of polymers 3rd edn, Elsevier, Amsterdam (1990) Chapter 4

35 Simha, R. and Boyer, R.F. J Chem Phys (1962) 371003

36 Puleo, A.C., Muruganandam, N. and Paul, D.R. J Polym Sci Polym Phys Ed (1989) 272385

37 Barbari, T.A., Koros, W.J. and Paul, D.R. J. Polym Sci Polym Phys Ed (1988) 26709

38 Muruganandam, N., Koros, W.J. and Paul, D.R. I Polym Sci Polym Phys Ed (1987) 251999

39 Min, K.E., Koros, W.J. and Paul, D.R. J Polym Sci Polym Phys Ed (1988) 261021

40 Stannet, V.T. Simple gases, and Fujita, H. Organic vapours above their glass transition temperature, and Kummins, C.A. and Kwei, T.K. Free volume and other theories Diffusion in Polymers (Eds J. Crank and G.S. Park) Academic Press, London (1968) Chapters 2,3 and 4

41 Bondi, A. Physical properties of molecular crystals, liquids and glasses Elsevier, Amsterdam (1968)

42 Askadskii, A.A. Predictions of physical properties of polymers, Polymer Yearbook (Eds R.A. Pethrick and G.E. Zaikv) Vol. 4, Harwood, London (1987) Chapter 1

43 Hensema, E.R., Mulder, M.H.V. and Smolders, C.A. $J$ Appl Polym Sci (1993) 492081 